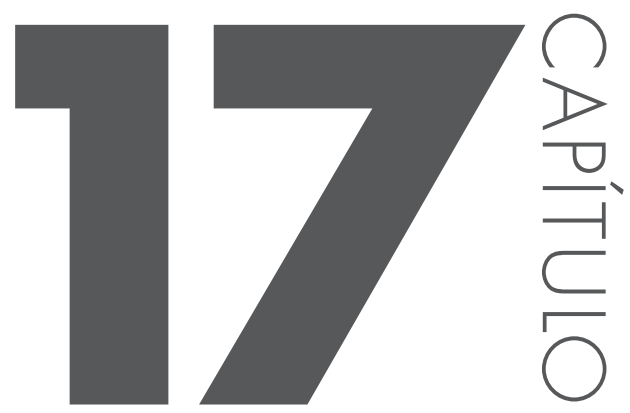

\title{
A INFLUÊNCIA DO MERCADO IMOBILIÁRIO NA PRODUC̣ÃO DO ESPAÇO URBANO EM ITUIUTABA (MG)
}

Chaves, Luciana Domingues '; Vieira Neto, José 2

1 Geógrafa. Mestranda do Programa de Pós-graduação em Geografia da Universidade Federal de Goiás/Regional Catalão; Bolsista CAPES; Núcleo de Estudos e Pesquisas Socioambientais -NEPSA/CNPQ

2 Géografo. Professor Dr. do Programa de Pós-graduação em Geografia da Universidade Federal de Goiás/Regional Catalão; Núcleo de Estudos e Pesquisas Socioambientais -NEPSA/CNPQ

* email: lucianachavesitba@gmail.com

\section{RESUMO}

Desde algumas décadas as discussões acerca da produção do espaço urbano têm ganhando cada vez mais notoriedade no âmbito acadêmico acarretando o aprofundamento dos debates teóricos e a realização de estudos empíricos frente às constantes transformações que vivenciamos cotidianamente nas cidades. Assim, este artigo foi escrito para proporcionar uma visão genérica da Dissertação intitulada "Produção do espaço urbano: a influência do mercado imobiliário em Ituiutaba (MG) no período de 2000 a 2014", que se encontra em desenvolvimento no âmbito do de Pós-graduação da Universidade Federal de Goiás/Regional Catalão, cujo objetivo consiste 
em compreender a relação entre produção do espaço urbano, dinâmica socioeconômica e a expansão do mercado imobiliário na cidade de Ituiutaba(MG) no período de 2000 a 2014.

Palavras-chave: Produção de Espaço Urbano, Mercado Imobiliário; Ituiiutaba

Chaves, Luciana Domingues; Vieira Neto, José; "A INFLUÊNCIA DO MERCADO IMOBILIÁRIO NA PRODUÇÃO DO ESPAÇO URBANO EM ITUIUTABA (MG)", p. 275-287 . In: Seminário de Pesquisa, Pós- Graduação e Inovação da Regional Catalão (2. : 2014 : Goiás) Coletânea Interdisciplinar em Pesquisa, Pós- Graduação e Inovação - Volume 1 : Estudos Ambientais, Território e Movimentos Sociais. Anais [livro eletrônico] / organizado por Adriana Freitas Neves, Idelvone Mendes Ferreira, Maria Helena de Paula, Petrus Henrique Ribeiro dos Anjos. São Paulo: Blucher, 2015. ISBN: 978-85-8039-109-1, DOI 10.5151/9788580391091-V1_Cap17 


\section{INTRODUC̣ÃO}

Os estudos urbanos em torno do papel do mercado imobiliário e do poder público tem ganhado na última década suma importância para a compreensão da produção do produção. Acredita-se que isto decorre do momento econômico atual que o Brasil se encontra, destacando-se no estímulo ao consumo, aumento de subsídios ao credito e financiamentos e, eventos esportivos como Copa do Mundo de 2014 e, Jogos Olímpicos de 2016. Assim, a discussão que colocará na pesquisa remete-se ao espaço urbano, mais especificamente ao seu processo de produção.

Fruto de um processo dinâmico, o espaço urbano é resultado das atuações dos diversos agentes que atuam neste, segundo anseios e necessidades próprias, o que, por consequência, acarretam práticas que o (re)produzem de modo desigual. Considerando-se tais pressupostos objetiva-se, na pesquisa em desenvolvimento, compreender a relação entre produção do espaço urbano, dinâmica socioeconômica e a expansão do mercado imobiliário na cidade de Ituiutaba(MG) no período de 2000 a 2014. Nossa abordagem esta pautada na (re)produção recente Desta, destaca-se um processo marcado pela atuação pela atuação do capital imobiliário e, os investimentos no setor habitacional subsidiados tanto pelos Governos Federal e Estadual, como pela iniciativa privada.

Para atingir o objetivo proposto pela pesquisa, serão realizados os seguintes procedimentos metodológicos: a) pesquisa teórica sobre as temáticas, urbano, cidade, produção do espaço urbano, planejamento urbano e mercado imobiliário, bem como da cidade de Ituiutaba, perpassando pela ótica de autores como Barretos (2012), Carlos (2008; 2013), Corrêa (2005 e 2013), Rolnik (2012), Villaça (2001), Chaves (1998; 2014), Lourenço (2005), Guimarães (1990 e 2010), Ferreira (2013), Mateus (2013), entre outros que se apresente de fundamental primazia para o trabalho; b) pesquisa documental junto Biblioteca Municipal Senador Camilo Chaves; Museu Antropológico de Ituiutaba (MUSAI); Galeria de Antiguidades de Ituiutaba; Base de Dados do Instituto Brasileiro de Geografia e Estatística entre outros, com a finalidade de realizar levantamentos bibliográfico, fotográfico, cartográficos, de dados e, de informações sobre a área de estudo, englobando aspectos demográficos, social e econômico; bem como do mercado imobiliário para o recorte temporal estabelecido; c) pesquisa de campo com a finalidade de fazer observações empíricas e registro fotográfico, de forma a analisar o tipo de uso e ocupação predominante nos diferentes setores da cidade, os quais propicia a produção desigual do espaço urbano. 
Cabe reforçar que a pesquisa está em andamento e por esse motivo não serão apresentados resultados concretos.

\section{LOCALIZAC̣ÃO E CARACTERIZAC̣ÃO DA ÁREA DE ESTUDO}

A cidade de Ituiutaba, recorte espacial deste estudo, é sede de município localizado na Mesorregião Geográfica do Triângulo Mineiro e Alto Paranaíba, mais especificamente na Microrregião de Ituiutaba (figura 1).

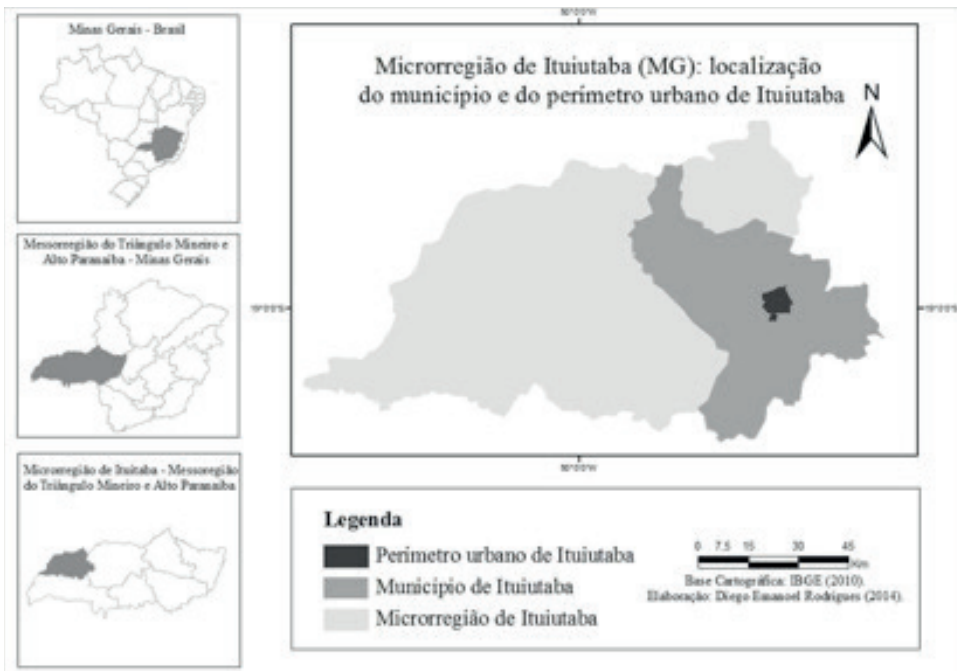

Figura 1. Microrregião de ltuiutaba (MG): localização do município e do perímetro urbano de ltuiutaba, 2014

Em linhas gerais, do ponto de vista econômico, nas décadas de 1960/70 a rizicultura atinge seu ápice e se consolida no cenário econômico do município de Ituiutaba. Assim, com base no capital originado pelo arroz,

[...] a cidade começou a melhor equipar-se com serviços de água, energia elétrica, comércio e serviços diversificados, expansão de loteamentos urbanos e novas atividades, que iria beneficiar a população, que crescia vertiginosamente nesse período [...] As mudanças no espaço urbano ocorreram paralelamente às do espaço rural: "levas" de trabalhadores nordestinos chegaram ao município de Ituiutaba e tornaram-se agentes transformadores do 
campo, responsabilizados pelas roças de arroz, milho e feijão [...] O Capital investido no campo teve retorno na cidade de modo gradual: cresceu o número de habitantes, residências e casas de comércios, serviços e indústrias ligadas à atividade agrícola (OLIVEIRA, 2003, p.16-17; 64).

Neste panorama de transformações há uma inversão dos dados em relação aos aspectos populacionais evidenciando-se maior número de pessoas vivendo na área urbana do município conforme demonstrado na tabela 1. Fato que culminou com os projetos governamentais desenvolvidos para a área do Cerrado, os quais desenvolveram o campo (grandes propriedades), propiciando o êxodo rural devido à mecanização do meio rural. Neste contexto, como nos aponta Oliveira (2003), houve a expansão de novos loteamentos urbanos, bem como emergiu novas atividades nos diferentes setores da economia para contemplar a população que crescia notoriamente neste período em Ituiutaba.

Tabela 1. Ituiutaba (MG): dinâmica da população total, e percentual da população urbana e rural (19502010)

\begin{tabular}{|c|c|c|c|c|c|}
\hline ANO & TOTAL & $\begin{array}{c}\text { POPULACÃO } \\
\text { URBANAA }\end{array}$ & POPULAC̣ÃO RURAL & $\begin{array}{l}\text { POPULACC̃̃O } \\
\text { URBANA (\%) }\end{array}$ & $\begin{array}{l}\text { POPULACÃO } \\
\text { RURAL (\%) }\end{array}$ \\
\hline 1950 & 53.240 & 10.113 & 43.127 & 19,00 & 81,00 \\
\hline 1960 & 68.218 & 30.698 & 37.520 & 45,00 & 55,00 \\
\hline 1970 & 64.528 & 46.784 & 17.744 & 72,50 & 27,50 \\
\hline 1980 & 74.247 & 65.153 & 9.094 & 87,75 & 12,25 \\
\hline 1991 & 84.577 & 78.205 & 6.372 & 92,46 & 7,54 \\
\hline 2000 & 89.091 & 83.853 & 5.238 & 94,12 & 5,88 \\
\hline 2010 & 97.171 & 93.125 & 4.046 & 96,00 & 4,00 \\
\hline
\end{tabular}

Fonte: Censos Demográficos - Instituto Brasileiro de Geografia e Estatística (IBGE): 1950, 1960, 1970,1980, 1991, 2000 e 2010. Org.: CHAVES, Luciana Domingues,2013.

$\mathrm{Na}$ primeira década de 2010, Ituiutaba passou por um processo marcado pela atuação do capital e do poder público no espaço urbano, os quais propiciaram significativas transformações na paisagem urbana, sobretudo através de investimentos e lançamento de novos produtos imobiliários bastantes elucidativos na reestruturação da cidade. A título de exemplo, citamse os investimentos subsidiados pelos governos federal e estadual, no setor da moradia popular, os quais redesenharam os limites urbanos. 


\section{ALGUNS APONTAMENTOS}

Desde algumas décadas as discussões acerca da produção do espaço urbano têm ganhando cada vez mais notoriedade no âmbito acadêmico acarretando o aprofundamento dos debates teóricos e a realização de estudos empíricos frente às constantes transformações que vivenciamos cotidianamente nas cidades. Sobre este tema, Corrêa (2005, p. 11), importante pesquisador do espaço urbano, destaca esse como sendo simultaneamente "fragmentado, articulado, condicionante social, cheio de símbolos e campo de lutas" e, portanto, tratase de "um produto social, resultado de ações acumuladas através do tempo, e engrenadas por agentes que produzem e consomem espaço". Trate- se de um processo conflituoso, pois a disparidade de interesses dos diversos agentes induz sua produção de forma desigual.

Corroborando-se em Corrêa (2013), Pinheiro (2011, p.37) contribui nesta discussão quando chama atenção para o fato de que "no contexto da acumulação de capital, a estruturação/organização do espaço urbano advém da relação de um conjunto de forças originadas por agentes produtores do espaço que atuam de forma particular às suas intencionalidades”. Esses agentes atuam de forma diferenciada e de acordo com seus interesses, apropriando-se do espaço, gerando um processo de reorganização constante deste, ou seja, um ininterrupto processo de reprodução.

Em relação, aos agentes produtores do espaço urbano, é indispensável esclarecer que na pesquisa em desenvolvimento, considera-se a proposição de Corrêa (2005), na qual estes são a) os proprietários dos meios de produção; b) os proprietários fundiários; c) os promotores imobiliários; d) o Estado e; e) os grupos sociais excluídos. Embora a ação de todos eles se dê conjuntamente no espaço urbano, nos ateremos nesse texto à ação dos promotores imobiliários, tendo em vista o objetivo geral do trabalho em andamento.

De acordo com Corrêa (2005), por promotores imobiliários, entende-se um conjunto de agentes que realizam parcialmente ou totalmente as seguintes operações: (a) incorporação; (b) financiamento; (c) estudo técnico; (d) construção ou produção física do imóvel e; (e) comercialização ou transformação do capital-mercadoria em capital-dinheiro.

A incorporação, é a operação-chave da promoção imobiliária; o incorporador realiza a gestão do capital-dinheiro na fase de sua transformação em mercadoria, em imóvel; a localização, o tamanho das unidades e a qualidade do prédio a ser construído são definidos na incorporação, assim como as decisões de 
quem vai construí-lo, a propaganda e a venda das unidades (CORRÊA, 2005, p.19).

Fica, evidente que a incorporação articula os demais agentes supracitados, uma vez que, pode compreender desde, a aquisição da terra até a venda do imóvel para o consumidor final. Barreto (2012) esclarece que a atividade empresarial de incorporação imobiliária é exercida pelo incorporador (pessoa física ou jurídica) o qual mobiliza fatores de produção necessários para a construção e a oferta das unidades imobiliárias no mercado. Para Franco; Gondo (1991) a figura do incorporador é aquele que com discernimento próprio financia, ou obtém o financiamento da obra; procura e efetiva a compra de terrenos aptos ao desenvolvimento de empreendimentos imobiliários; idealiza por intermédio do estudo técnico o projeto de edificação, levando-o à aprovação pelas autoridades competentes; constrói a estrutura física do imóvel ou contrata firmas especializadas, sob sua supervisão e comercializa os imóveis ou delega por meio de imobiliária de imóveis a negociação com o comprador final.

É fora de dúvida que a atuação dos promotores imobiliários está diretamente ligada à valorização diferencial das áreas no interior do tecido urbano. De acordo com Campos (2011), ao selecionar determinadas frações do espaço urbano para a implementação de empreendimentos (residencial, comercial) os promotores imobiliários conduzem o processo de formação dos sobrelucros de localização, a qual se torna conjuntamente com outros fatores (investimentos públicos/privados, infraestrutura) determinante no valor da terra urbana.

Villaça (2001), importante pesquisador do espaço intraurbano, chama atenção para o fato da terra urbana, permitir maior ou menor valorização pelo acesso que sua localização, propicia a todo sistema urbano, a toda a cidade. Usa como exemplo os lotes não edificados, os quais tem seu valor aumentando tanto por investimentos privados e/ou públicos; infraestrutura em seu entorno quanto por sua localização. Com base nisso traz-se uma breve reflexão sobre a cidade de Ituiutaba, objeto de pesquisa do trabalho, nos últimos dez anos Esta ampliou a valorização da terra não edificada. Consolidado como o período referencial de grandes modificações em seu contexto urbano, o ano de 2005 marca a desconcentração dos valores mais elevados de lotes não edificados do setor central para o setor sudeste, mais especificamente para um bairro até então visto como periférico, tendo em vista sua infraestrutura precária. Logo, após a especulação e confirmação da implantação da Unidade Superior de Ensino, Universidade Federal de Uberlândia-Campus Pontal no presente bairro, os proprietários das áreas circunvizinhas ao local previsto para sua construção incorporaram expectativas de aumento do preço de seu(s) lote(s) 
não edificado(s). Movimento valorativo verificado nos anúncios do principal classificado de circulação local e regional, que contempla a oferta das principais imobiliárias da cidade. Assim, tem-se no ano 2000 um terreno de $500 \mathrm{~m}^{2}$, vendido por $\mathrm{R} \$ 1.000,00$, parcelado em 11 prestação, em contrapartida, um terreno de $312,5 \mathrm{~m}^{2}$ era ofertado por $\mathrm{R} \$ 4.000,00$ no ano de 2005 . Observa-se a inserção da lógica capitalista da especulação imobiliária, e, por conseguinte a valorização e elevação dos preços dos terrenos, mediante a melhoria de sua localização.

Outra contribuição importante é oferecida por Santos (2007), esse revela toda importância da localização bem como da acessibilidade, ou seja, não se trata de pagar a terra urbana, mas por sua localização. Estudos realizados por Carlos (2013) reforça a localização como ponto de partida para a determinação do preço do solo urbano, atrelada a outros fatores como acesso dos lugares ditos privilegiados; acesso infraestrutura básica (sistemas de serviços urbanos, transporte e comunicação); privacidade e, secundariamente, os fatores vinculados às características físicas como relevo, dimensões da área, tende a auferir lucro no valor da terra, como também pode causar queda nos preços, devido ausência parcial e/ou total dos mesmos.

Mellazo (1993), em seu estudo sobre mercado imobiliário, o qual se constitui lócus de negociação de imóveis edificados e não edificados, acrescenta que o conjunto de fatores (localização, de áreas dotadas de infraestrutura, facilidade de acesso, equipamentos de usos coletivos, presenças de áreas verdes entre outras) é que distingue qualitativamente uma parcela do solo, dando-lhe certo valor e diferenciando-o em relação à aglomeração na qual se insere.

A partir dessas concepções é possível afirmar que a cidade é produzida não como um todo, ou seja, homogênea, mas como partes que se formam em tempos diferentes. Sobre o assunto Barbosa (2005), em sua pesquisa acerca da produção do espaço urbano e transformações urbanas pontua que a atuação e interesses dos agentes produtores do espaço urbano, manifestam a divisão social do espaço. Enquanto algumas áreas são ditas como espaços rápidos, resultado do conjunto de fatores (infraestrutura, acesso a equipamentos de usos coletivos entre outros) que obtêm outras desprovidas de tais bens configura-se como espaços lentos. Trata-se do processo de valorização/desvalorização da terra urbana que, consequentemente mostra as desigualdades e a segregação urbana que o preço desta origina, isto é, deixa transparecer as diferenças de classes existentes nas cidades.

Sobre o assunto, Rolnik (2012), ao falar sobre a questão da segregação urbana, acrescenta que a cidade se assemelha a um quebra-cabeça, onde cada indivíduo conhece seu lugar, mas se sente como um estranho nos demais. Esse 
fato leva-nos a concluir que a ocupação do espaço urbano se dá de forma seletiva, na qual a diferenciação das classes sociais, condicionada pela renda reproduz a divisão social e econômica deste espaço. Para a autora, além das classes/grupos sociais existe outro elemento relevante na determinação de ocupação do solo urbano, a intervenção do Estado. "Quando falamos em regiões nobres e regiões pobres, nos referimos a espaços equipados com o que há de mais moderno em matéria de serviços urbanos e espaços onde o Estado investe pouquíssimo na implantação destes mesmos equipamentos" (ROLNIK, 2012, p. 58).

Diante dos argumentos de Rolnik (2012) considera-se que ao determinar a instalação do conjunto de infraestrutura e equipamentos coletivos, o Estado interfere diretamente e/ou indiretamente na orientação do uso do solo do espaço urbano, bem como em sua valorização/desvalorização. Pinheiros (2011), em sua pesquisa sobre reprodução do capital e metamorfoses espaciais, acrescenta que além de interferir na forma de ocupação do solo urbano, o Estado interfere no mercado imobiliário, por intermédio do investimento em infraestrutura em um espaço desvalorizado, cria novas oportunidades de incorporação imobiliária. Assim, os investimentos sociais são transformados em instrumentos de valorização das terras urbanas, ao mesmo tempo em que, pode anexar novas áreas (industrial, comercial, residência) ao espaço urbano, de modo a propiciar oscilações no mercado imobiliário devido às mudanças contínuas do tecido urbano.

Sobre o crescimento do mercado imobiliário nacional, Filho (2014) destaca que a partir da segunda metade da ultima década, o mercado imobiliário tem apontado crescimento vertiginoso devido a fatores como: a) maior oferta de crédito, tanto para o incorporador, como para o consumidor final; b) aumento da renda familiar; c) redução da taxa básica de juros, adotada pelo Banco Central; d) tentativa do Governo Federal em erradicar o déficit habitacional por meio do Programa Minha Casa Minha Vida (PMCMV).

O Programa Federal Habitacional Minha Casa Minha Vida, estruturado na política de alavancar o mercado imobiliário, foi lançado pela Lei ${ }^{\circ} 11.977$ de julho de 2009, com o objetivo de construir um milhão de novas moradias e, criar mecanismo de incentivo à produção e aquisição dessas novas unidades habitacionais. Nessa dinâmica recente habitacional, Ituiutaba se destaca no cenário regional como uma das cidades que conseguiu significativos investimentos na habitação, foram nove conjuntos habitacionais, de diferentes tamanhos e localizados em diferentes setores/bairro da cidade, os quais condicionaram sua expansão horizontal, redesenhando o urbano como um mosaico de espaços da inclusão e da exclusão social. 
Para fechar esse texto sem, contudo, concluir a análise e as discussões aponta-se que ao analisar a dinâmica da produção do espaço urbano e a atuação dos seus agentes produtores, é possível apreender como a sociedade intrínseca ao capital se apropria deste espaço conforme suas especificidades.

\section{CONSIDERAC̣ÕES FINAIS}

Conforme versado na seção introdução, o objetivo proposto para o estudo consiste em compreender a relação entre produção do espaço urbano, dinâmica socioeconômica e a expansão do mercado imobiliário na cidade de Ituiutaba (MG) no período de 2000 a 2014. Para tanto, será realizado o tripé: a) pesquisa teórica; b) pesquisa documental e, c) pesquisa de campo.

No presente artigo não se apresenta resultados conclusivos, uma vez, que a pesquisa está em andamento, entretanto, por intermédio dos procedimentos metodológicos visa-se a confirmação ou refutação da seguinte hipótese, com a construção da Unidade Superior de Ensino, bem como, dos investimentos no setor habitacional a produção do espaço urbano da cidade de Ituiutaba nos últimos dez anos deu-se sob a lógica da valorização de imóveis; na seletividade de investimentos privados nos segmentos comercial e residencial e no aumento do preço da terra não edificada.

Por fim, mas não menos importante, destaca-se que com a realização da pesquisa busca-se contribuir para o entendimento da dinâmica local, fornecendo desde modo alguns fundamentos para estudos posteriores. 


\section{Title: The Influence Of The Market Real Estate In The Production Of Urban Space In Ituiutaba (Mg)}

\section{Abstract}

Since some decades the discussions on the production of urban space are gaining increasingly notoriety in the academic sphere, causing the deepening of theoretical debates and conducting empirical studies in the face of constant changes that we experience daily in cities. Thus, this article was written to provide a general overview of the dissertation entitled "Production of urban space: the influence of the housing market in Ituiutaba (MG) in the period 2000-2014", which is under development within the Pós-gradução da Universidade Federal de Goiás/Regional Catalão, whose goal is to understand the relationship between urban space production, socio-economic dynamics and the expansion of the real estate market in the city of Ituiutaba (MG) in the period 2000-2014.

Keywords: Production of Urban Space. Real Estate Market. Ituiutaba(MG). 


\section{REFERÊNCIAS}

BARRETO, Tainah Ramos. Incorporação imobiliária e o código de defesa do consumidor: a responsabilidade do fornecedor pelo vício e fato do produto. 2012. 63f. Trabalho de conclusão de curso (Bacharel em Direito) - Faculdade de Ciências Jurídicas e Sociais, Centro Universitário de Brasília, Brasilia, 2012.

CAMPOS, Paola Rogedo. 0 precco da terra urbana e moradia de baixo custo. In: Mendonça, Jupira Gomes de; COSTA, Heloisa Soares de Moura (orgs.). Estado e Capital Imobiliário: convergências atuais na producão do espaço urbano brasileiro. Belo Horizonte: C/Arte, 2011. p. 63-79.

CARLOS, Ana Fani Alessandri. A (re)produção do espaço urbano. 1 ed., 1 reimp. São Paulo: EDUSP, 2008.

CARLOS, Ana Fani Alessandri. A cidade. 9 ed., 1 reimp. São Paulo: Contexto, 2013. (Coleção Repensando a Geografia).

CARLOS, Ana Fani Alessandri. A prática social urbana como segregação e o "direito à cidade" como horizonte utópico. In: VASCONCELOS, Pedro de Almeida; CORRÊA, Roberto Lobato (orgs.). A cidade contemporânea: segregação espacial. São Paulo: Contexto, 2013. p. 95-110.

CARLOS, Ana Fani Alessandri. Da "organização" à produção do espaço no movimento do pensamento geográfico. In: ; SOUZA, Marcelo Lopes; SPOSITO, Maria Encarnação Beltrão (orgs.). A produção do espaço urbano: agentes e processos, escalas e desafios. led., 2 reimp. São Paulo: Contexto, 2013. p. 53-73.

CHAVES, Camilo. Caiapônia: romance da terra e do homem do Brasil Central. 3ed. Ituiutaba: [s.n], 1998.

CHAVES, Luciana Domingues. Produção do espaço urbano e mercado imobiliário: um estudo de caso de Ituiutaba - MG. 2014. 81f. Trabalho de conclusão de curso (Graduação em Geografia) Faculdade de Ciências Integradas do Pontal, Universidade Federal de Uberlândia, Ituiutaba, 2014.

CORRÊA, Roberto Lobato. 0 espaço urbano. 4 ed. São Paulo: Ática, 2005.

CORREEA, Roberto Lobato. Segregação socioespacial e centralidade urbana. In: VASCONCELOS, Pedro de Almeida; CORRÊA, Roberto Lobato (orgs.). A cidade contemporânea: segregação espacial. São Paulo: Contexto, 2013. p. 39-59.

CORRÊA, Roberto Lobato. Segregação socioespacial e centralidade urbana. In: VASCONCELOS, Pedro de Almeida; CORRÊA, Roberto Lobato (orgs.). A cidade contemporânea: segregação espacial. São Paulo: Contexto, 2013. p. 39-59.

CORRÊA, Roberto Lobato. Sobre agentes sociais, escala e produção do espaço: um texto para discussão. In: CARLOS, Ana Fani Alessandri; SOUZA, Marcelo Lopes; SPOSITO, Maria Encarnação Beltrão (orgs.). A produção do espaço urbano: agentes e processos, escalas e desafios. led., 2 reimp. São Paulo: Contexto, 2013. p. 41-51.

CORRÊA, Roberto Lobato. Sobre agentes sociais, escala e productão do espaço: um texto para discussão. In: CARLOS, Ana Fani Alessandri; SOUZA, Marcelo Lopes; SPOSITO, Maria Encarnaç̃ão Beltrão (orgs.). A produção do espaço urbano: agentes e processos, escalas e desafios. led., 2 reimp. São Paulo: 
Contexto, 2013. p. 41-51.

FERREIRA, Leilaine de Fátima. Programa Minha Casa Minha Vida em Ituiutaba (MG): uma análise dos conjuntos habitacionais Buritis, Canaã I e Canaã II. 2013. 90f. Trabalho de conclusão de curso (Graduação em Geografia) - Faculdade de Ciências Integradas do Pontal, Universidade Federal de Uberlândia, Ituiutaba, 2013.

FILHO, Hyltom Pinto de Castro. Breve estudo sobre a atividade de incorporação imobiliária. 2011. Disponivel em: http://jus.com.br/artigos/18539/breve-estudo-sobre-a-atividade-deincorporacao-imobiliaria. Acesso em 02/11/2014.

FRANCO, João Nascimento; GONDO, Nisske. Incorporações Imobiliárias. $3^{a}$ ed. São Paulo: Revista dos Tribunais, 1991.

GUIMARÃES, Eduardo Nunes. Formação e desenvolvimento econômico do Triângulo Mineiro: integração nacional e consolidação regional. Uberlândia: EDUFU, 2010.

GUIMARÃES, Eduardo Nunes. Infra-estrutura pública e movimento de capitais: a inserção do Triângulo Mineiro na divisão inter-regional do trabalho. 1990. 224f. Dissertação (Mestrado em Desenvolvimento e Planejamento Regional) - Universidade Federal de Minas Gerais, Belo Horizonte, 1990.

LOURENC, O, Luís Augusto Bustamante. A oeste das minas: escravos, índios e homens livres numa fronteira oitocentista, Triângulo Mineiro (1750-1861). Uberlândia: EDUFU, 2005.

MATEUS, Renato. A dinâmica da agricultura no cerrado: do apogeu do arroz à modernização do campo na região de Ituiutaba (MG) - 1946-1974. 2013. 84f. Trabalho de conclusão de curso (Bacharelado em História) - Faculdade de Ciências Integradas do Pontal, Universidade Federal de Uberlândia, Ituiutaba, 2013.

MELLAZO, Everaldo. Mercado imobiliário, expansão territorial e transformações intraurbanas: 0 caso de Presidente Prudente - SP. 1993. 141f. Dissertação (Mestrado) - Instituto de Pesquisa e Planejamento Urbano e Regional, Universidade do Rio de Janeiro, Rio de Janeiro, 1993.

OLIVEIRA, Bianca Simoneli de. Ituiutaba (MG) na rede urbana tijucana: (re)configurações sócio-espaciais no período de 1950 a 2000. 2003. 204f. Dissertação (Mestrado em Geografia) Instituto de Geografia, Universidade Federal de Uberlândia, Uberlândia, 2003.

PINHEIRO, Mariana de Vasconcelos. Reproduccão do capital e metamorfoses espaciais: um estudo da verticalização de Ponta Negra, Natal/RN. 2011. 188f. Dissertação (Mestrado em Geografia) - Universidade Federal do Rio Grande do Norte, Natal, 2011.

ROLNIK, Raquel. 0 que é cidade. 4 ed ${ }^{\circ}$. São Paulo: Brasiliense, 2012.

SANTOS, Milton. 0 espaço do cidadão. São Paulo: Nobel, 2007.

VILLAÇA, Flávio. Espaço intra-urbano no Brasil. 2 ed. São Paulo: Studio Nobel/FAPESP, 2001. 
Seminário de Pesquisa, Pós-Graduacãoo e Inovação da Regional Catalão 